\title{
A novel X-ray radiography approach for the characterization of granular activated carbons used in the rum production
}

\author{
Jeamichel Puente Torres ${ }^{1}$, Harold Crespo Sariol ${ }^{2}$, Jan Yperman ${ }^{3 *}$ (D) Ángel Brito Sauvanell ${ }^{2}$, Robert Carleer ${ }^{3}$ \\ and José Navarro Campa ${ }^{4}$
}

\begin{abstract}
Background: X-ray methods have proven to be reliable, accurate and sensitive techniques to study activated carbons in order to define its porous structure and functionality groups.

Methods: For the first time, the characterization of the exhaustion level of granular activated carbon (GAC) used in rum production applying methods based on X-ray technology has been explored. In this work, the exhaustion degree of GAC from a target rum "filter" using X-ray radiography is evaluated. Digital processing techniques on $X$-ray radiography images from eight consecutive GAC layers of the industrial rum filter have been assessed.

Results: The exhaustion profile for the rum "filter" applying X-ray radiography images processing is correlated with thermal desorption - gas chromatography/ mass spectrometry (TD-GC/MS) chromatograms. The total of pixel detected in the radiographic X-ray images (grey-scale) is related with the total amount of organic adsorbed compounds in the exhausted GAC.

Conclusion: The proposed method opens possibilities for the rum producers to improve the management and economical use of the activated carbon at industrial scale. The proposed technique can be applied in the assessment of other adsorption systems such as: determining the poisoning level of catalyst material, the GAC exhaustion level in organic polluted water treatments, and the GAC regeneration degree and exhaustion studies on hemo-perfusion GAC cartridges.
\end{abstract}

Keywords: Activated carbon, X-ray radiography, Digital image processing, Rum, Porosity

\section{Background}

Rum is a fairly tasteless and neutral spirit, traditionally produced in the Caribbean and Central American countries. In Cuba, the rum production starts by distilling a kind of colorless primary rum (known as aguardiente) which is aged in barrels of white oak wood during a timed period in order to transform and improve its sensorial characteristics. The ageing process (maturation) results in changes of the aguardiente: a light amber color appears; taste softens and a pleasant aroma is produced (Queris 2007). During this stage, these sensorial changes are obtained by complex chemical reactions between the

\footnotetext{
* Correspondence: jan.yperman@uhasselt.be

${ }^{3}$ Research group of Applied and Analytical Chemistry, Hasselt University,

Agoralaan building D, 3590 Diepenbeek, Belgium

Full list of author information is available at the end of the article
}

aguardiente and the oak wood (Queris 2007; Reazin 1981; Nabeta et al. 1983; Otzuka and Morinaga 1965). However, taking into account the amount of compounds involved, a huge number of possible reaction mechanisms and products can be found. Rums are a complex mixture of organic substances: 186 organic compounds have been identified (Jorge 2007; Jorge et al. 2012). Therefore, the study of the ageing process is quite complicated (Jorge 2007; Jorge et al. 2012; Sponholz 1990; Suomalainenen and Nykanen 1970; Parfait and Jouret 1975; Nykanen and Nykanen 1991; De Souza et al. 2006; Nykanen and Moring 1984; Sarni et al. 1990; Queris and Sánchez 1998; Maga 1989; Artajona 1991). After the ageing process, the operation of percolation "filtration" of the aged aguardiente using granular activated carbon (GAC) is essential to reach the desirable organoleptic features in 
Cuban rum (Queris 2007; Reazin 1981; Nabeta et al. 1983; Otzuka and Morinaga 1965). This operation is meticulously monitored by the rum taste experts (rum masters). GAC is used to remove/balance some organic compounds that affect the sensorial quality and organoleptic characteristics in the final product (Queris 2007; Reazin 1981; Nabeta et al. 1983; Otzuka and Morinaga 1965).

Fixed bed of GAC is placed in cylindrical contactors where the aged aguardiente is applied at the top of the filter, flows downward through the carbon bed, and is withdrawn as "filtered aged aguardiente" at the bottom of the column. As the liquid flows through the column, the compounds are adsorbed onto the GAC from the contactor's top to the bottom (Ferhan and Aktas 2011; Worch 2012; Thomas and Barry 1998; Schiith et al. 2002). When GAC become exhausted in the rum production they are removed and replaced by fresh or regenerated GAC. Different quantitative analytical methods for the characterization and quantification of the exhaustion level of GAC used in rum production have been recently published (Crespo Sariol et al. 2016a, 2016b, 2016c; Crespo Sariol et al. 2017a, 2017b). Based on these methods, a study of the exhaustion level in industrial rum filter demonstrated that a part of the GAC near to the filter's bottom can be reused as its exhaustion degree is significantly less in comparison with the GAC layers near to the top. On the other hand, for the exhaustion degree characterization in exhausted GAC in rum production, the classical techniques based on gas adsorption isotherms will not provide reliable results as the pretreatment (outgassing) of the samples imposes severe changes not only to the sample of exhausted GAC to be analyzed but also to serious damages to the analytical instrument used (Crespo Sariol et al. 2017b, 2017a; Sigmund et al. 2016). Therefore, an alternative, specific, fast and robust analytical method to determine the exhaustion level of GAC in rum production is always welcome due to the derived economic and environmental advantages for rum producers in order to optimize the GAC exploitation and regeneration in the rum industry.

Although high-tech analytical methods based on X-ray, such as X-ray photoelectron spectroscopy (XPS) and small-angle X-ray scattering, have been widely applied for studying structures and functional groups of carbonaceous materials (Rouquerol et al. 2014; Juan et al. 2008; Klobes and Meyer 2006; Marsh and Rodriguez-Reynoso 2006). The characterization of the exhaustion level of GAC used in rum production applying methods based on X-ray technology has not been explored yet. For studying activated carbons, X-ray-based methods proved to be trustable, accurate and sensitive techniques to define porous structures and functionality groups on the carbon surface in order to estimate its properties and applications. X-rays are ionization electromagnetic radiation which is produced by accelerating electrons using a voltage gradient between 0.124 to $124 \mathrm{kV}$ to be impacted against a heavy metal (high atomic number). The photonic radiation beam produced in the process is then sent to the material (target) to be analyzed. The penetration depth of photonic radiation in the material decreases with increasing atomic number, so there is a better spatial resolution for heavier elements (XPS). The spatial resolution improves with decreasing voltage to an optimum of $0.2 \mathrm{~nm}$ at $5 \mathrm{keV}$ (Rouquerol et al. 2014; Juan et al. 2008; Klobes and Meyer 2006; Marsh and Rodriguez-Reynoso 2006). For instance, the solid state detectors normally used in scattering electron microscopy have sufficient energy resolution to identify elements with adjacent atomic numbers. However, they are unable to detect elements whose atomic number is less than 9, because low-energy X-rays are absorbed by the window protecting the detector element. Lighter elements can be detected in dedicated systems where the window is very thin or can be removed, or by a wavelength-dispersive system. Since the graphene sheets in activated carbons are finite and have defects, as seen from $\mathrm{X}$-ray scattering, it is obvious that they are terminated by heteroatoms, such as: $\mathrm{O}, \mathrm{N}, \mathrm{S}$, and $\mathrm{P}$. These atoms generate heterogeneities in the wall adsorbate interaction, and thus, their inclusion is essential for the adsorption properties of carbon materials. To include heteroatoms in models of amorphous carbons, we must know which and how many functional groups a specific carbon material contains and where they are located. X-ray photoelectron spectroscopy (XPS) uses X-rays to eject core electrons from carbon, oxygen, nitrogen, or other heteroatoms. The binding energy of the core electron is measured. Thus, XPS is sensitive to the atom type and to the way this atom is bound to its environment (Juan et al. 2008).

Although the above described X-ray methods are a powerful tool for the activated carbon study, their use to characterize the exhaustion level of the GAC applied in the rum production process is perhaps unpractical as the technological facilities of rum producers are limited. However, knowing the sensibility of activated carbons to $\mathrm{X}$-ray action, X-ray radiography coupled with a proper digital image processing method as proposed in this paper can be used to characterize the exhaustion level of the GAC. In that case, a conventional X-ray radiography (commonly used for medical diagnosis) can be applied as an alternative, suitable and fast predicting method for characterizing the exhaustion degree of GAC in the rum production process. As its use is in a preliminary state, the optimum value of energy found for the application of the X-ray radiography technique $(22 \mathrm{keV}-125 \mathrm{mAs})$ was now limited by the current X-ray equipment used for medical diagnoses in Cuba to obtain digital radiologic images. The used X-ray equipment cannot emit energy under $20 \mathrm{keV}$, as lower energies have no sense for obtaining a useful medical image. However, it is already 
demonstrated that as the energy decreases, less amount of GAC will be needed to obtain higher differences in the grey scale. Improvements can thus be realised if the amount of needed GAC to obtain greater differences in the grey scale can be optimised by changing the milliarcsecond value with a constant energy value and if more suitable equipment is available.

The minimum needed voltage to produce an X-ray beam can be determined by the following equation

$$
\lambda_{\min }=\frac{1240(\mathrm{kV} \cdot \mathrm{pm})}{V}
$$

where

$\lambda_{\text {min }}$ : minimal wavelength for X-ray spectra $\left(0.01-10 \mathrm{~nm}=10-10^{4} \mathrm{pm}\right)$.

$V:$ voltage for the electrons' acceleration (in volts).

The X-rays produced by a voltage less than $22 \mathrm{kV}$ or higher than $120 \mathrm{kV}$ are not useful to obtain radiologic images. Therefore, $22-120 \mathrm{kV}$ is the proper range for a conventional radiological diagnosis. In this range, the predominant interaction effect with the material to be analyzed is the photoelectric effect as shown in Fig. 1.

Since the photoelectric effect is predominant for the voltage used for the clinical X-ray radiography, the law that rules the photon attenuation can be expressed by Eq. (2) (Cunningham 1986).

$$
N=N_{0} e^{-\mu x}
$$

where

$N$ : final Intensity or number of attenuated photons (dimensionless)

$N_{0}$ : initial Intensity or number of incident photons (dimensionless)

$\mu$ : linear absorption coefficient (in $\mathrm{mm}^{-1}$ )

$x$ : sample thickness (in mm)

Analyzing Eq. (2), we can deduce that the final intensity $N$ (attenuated photons) coming out from the

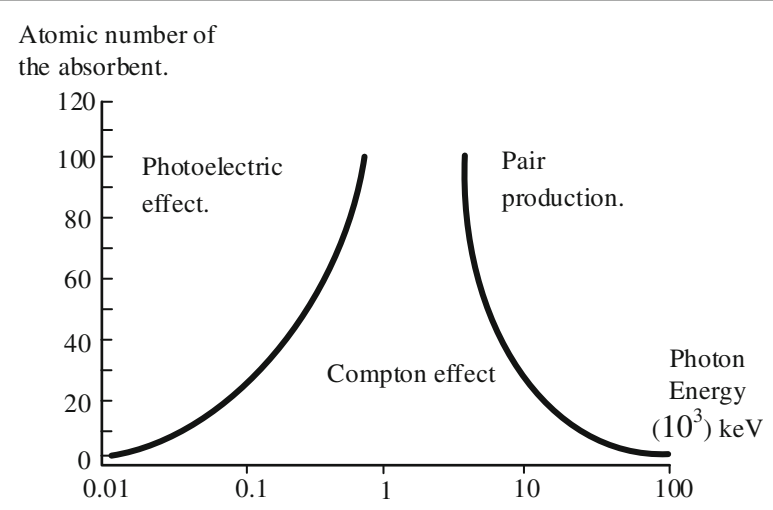

Fig. 1 Main interactions between photons and the matter (adapted from Cherny Jr. (1993)) analyzed material of thickness $x$ is directly dependent of the initial intensity $N_{0}$ (incident photons), $x$ and the linear absorption coefficient $\mu$ which depends on the characteristics of the material such as the atomic number $(Z)$ and its density $(\rho)$ and can be considered constant.

A simplified schematic diagram of this phenomenon in correspondence with Eq. (2) is presented in Fig. 2.

In Fig. 2, it is noticeable that scattered photons also escape from the material with different trajectories which are not directly captured by the detector (Fig. 2). The photons registered by the detector are just the photons that cross through the material without suffering any interaction, reaching the detector with the same initial energy. In contrast, the scattered photons interact with the material, changing its trajectory and coming out from the material at lower energy. The scattered photons are not relevant from a radiological viewpoint; they can create problems on the radiological images focusing. This inconvenience can be solved using antidiffusion grids which are installed in the X-ray apparatus eliminating about $90 \%$ of this radiation.

$\mathrm{X}$-rays are among the oldest source of electromagnetic radiation used for imaging. Medical images utilize several different physical principals or image modalities for is formation. An X-ray image obtained from the exposition of the matter to the X-rays provides a shadow of intervening structures (Semmlow 2004) as a direct function of its density $(\sigma)$ and atomic number $(Z)$. In digital radiography, digital images are obtained by two principal methods: (1) by digitalizing the X-ray film or (2) by having the X-ray that pass through the patient fall directly onto devices (such a phosphor screen) that converts $\mathrm{X}$-rays to light (Gonzales et al. 2004). The light signal in turn is captured by a light-sensitive digitalizing system. The digitalized X-ray image is a grey-scale matrix that can be in different formats depending on the nature of the image. For binaries or intensity images, image histogram constitutes a useful tool for analysing the characteristics of the resultant image, providing important information about the intensity levels and the total of pixels in the image. Other powerful methods for imaging

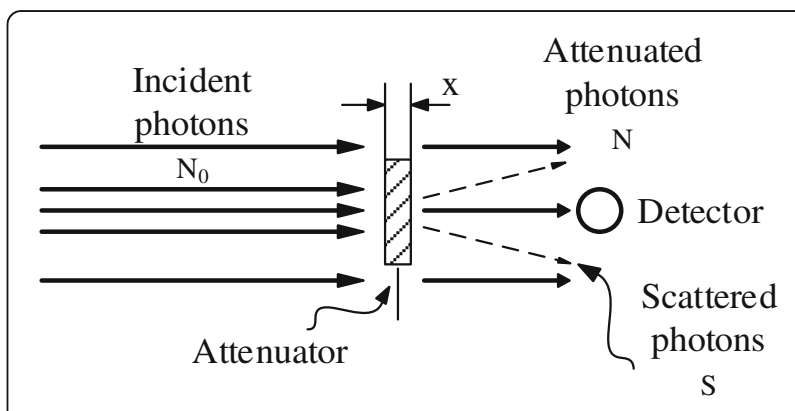

Fig. 2 Schematic diagram of photons interacting with a material (adapted from Cunningham (1986)) 
processing are linear filtering and spectral analysis using the two-dimensional version of the Fourier transformer (Gonzales et al. 2004; Gonzales and Woods 2002; Semmlow 2004). The use of the two-dimensional Fourier transformer is based on the consideration of an image as a result of the sum of infinite sinusoids or complex exponentials in two dimensions: the direction $M$ (number of rows in the image matrix) and direction $\mathrm{N}$ (number or columns in the image matrix). Since the X-ray methods have been successfully applied to determining functional groups on the carbonaceous surfaces, the use of digital images processing on digital X-ray radiography can be an interesting and suitable method to be explored in order to characterize the exhaustion level of GAC of rum production.

In this work, a novel method for the characterization of exhaustion level of the GAC used in rum production at an industrial-scale based on the digital processing of images obtained by a common X-ray radiography are evaluated in order to determine the exhaustion profile of GAC in a target rum filter.

\section{Methods}

\section{GAC samples}

An industrial filter (previously declared as "out of operation" by exhaustion) from the major rum producer in Cuba was used in order to obtain eight GAC samples at different layers (positions) in the carbon bed from the filter's top to the bottom according to the following order (Fig. 3): top $(0 \mathrm{~m}), 0.2,0.4,0.6,0.8,1,1.3 \mathrm{~m}$ and bottom $(1.5 \mathrm{~m})$ (Crespo Sariol et al. 2017b, 2017a). For comparison, a sample of virgin GAC was also characterized.

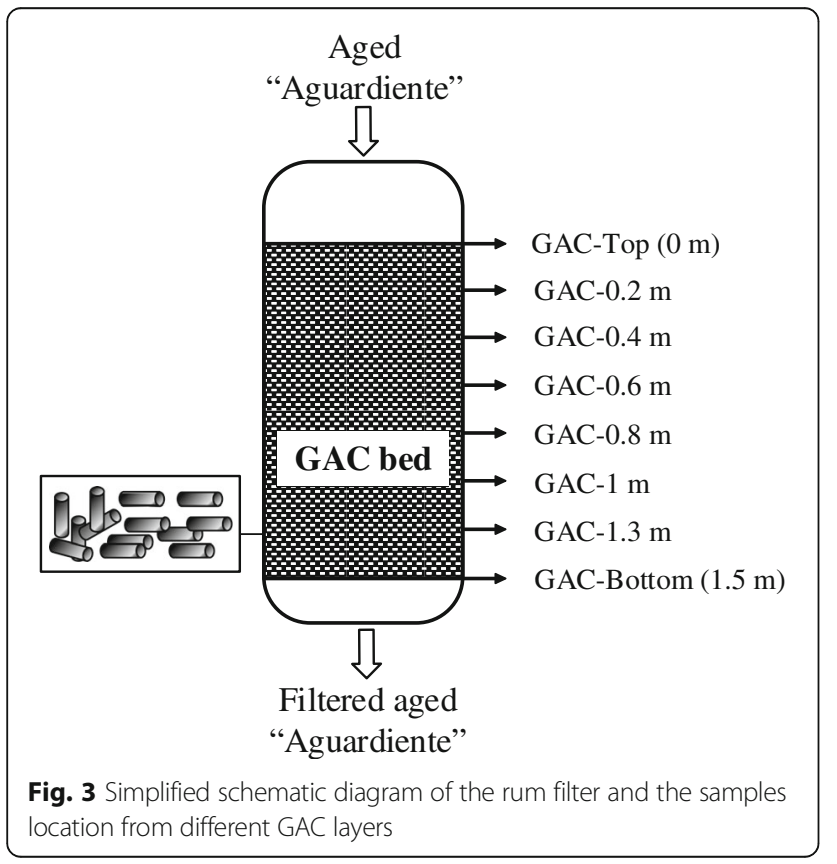

The GAC samples in different positions were labeled in accordance with Fig. 3: GAC-Top, GAC-0.2 to GAC1.3 and GAC-Bottom. The sample GAC-Top is the most exhausted GAC in the rum filter; the others have less exhaustion degree in a decreasing order. The closer to the bottom, the less its exhausted condition is (Crespo Sariol et al. 2017b, 2017a).

\section{Sample characterization}

Selected GAC samples were characterized using Thermal desorption TD-GC/MS as described in Crespo Sariol et al. (2017b, 2017a). Analyses were performed on a Trace GC Ultra gas chromatograph coupled with a DSQ-II mass spectrometer (Thermo Scientific). Samples were introduced in a Double Shot Pyrolyser PY-2020iD (Frontier Lab) in desorption mode $\left(100-450{ }^{\circ} \mathrm{C}\right)$. The GC-column was $30 \mathrm{~m}$ DB-5MS $0.25 \mathrm{~mm} \times 0.25 \mu$ (Agilent Technologies), and the GC was programmed from $35^{\circ} \mathrm{C}(1 \mathrm{~min})$, ramped at $12{ }^{\circ} \mathrm{C} /$ min to $320{ }^{\circ} \mathrm{C}$ (for $10 \mathrm{~min}$ ). The quadrupole mass spectrometer was scanned $33-550 \mathrm{amu}$ in $0.5 \mathrm{~s}$.

\section{Sample preparation}

In order to eliminate dust, samples were sieved using a WQS vibrating screen $\left(0.3 \mathrm{~mm} / 3000 \mathrm{~min}^{-1}\right)$. Prior analysis, the samples were dried applying ASTM Standard Test Methods for moisture determination in Activated Carbon (ASTM 2011). Samples were refreshed in a silica-gel desiccator till being measured (Crespo Sariol et al. 2017b, 2017a).

\section{X-ray radiography experiments}

$\mathrm{X}$-ray radiographies were performed at three different energies. Experiments applying 22 and $30 \mathrm{keV}-125 \mathrm{mAs}$ were conducted in a TOSHIBA Mamorez-mgu 100d X-ray apparatus (used for mammography). X-ray experiments at energy of $40 \mathrm{keV}-4 \mathrm{mAs}$ were carried out in a TOSHIBA KXO-36 s (used for clinical general radiography). As the $\mathrm{mAs}$ determines the number of incident photons, in X-ray diagnostics machines, the mAs is reduced when the energy $(\mathrm{keV})$ is too high (this is the case when $40 \mathrm{keV}$ is applied), not only to protect the X-ray filament but also obtaining less differences in the GSI between the different samples. As more photons passes through the material using $125 \mathrm{mAs}$ at $40 \mathrm{keV}$, darker images are obtained with less differences, making the experiment useless. Decreasing the milliarc-second is the way to obtain major differences in the GSI when the $\mathrm{keV}$ is increased up to $40 \mathrm{keV}$. The focus distance applied was $60 \mathrm{~cm}$ for all experiments.

\section{Experimental set-up description}

The $\mathrm{X}$-ray radiographies were performed using an X-ray cuvette (Fig. 4). The cuvette was made of transparent acrylic material. One side of the cuvette was labeled 


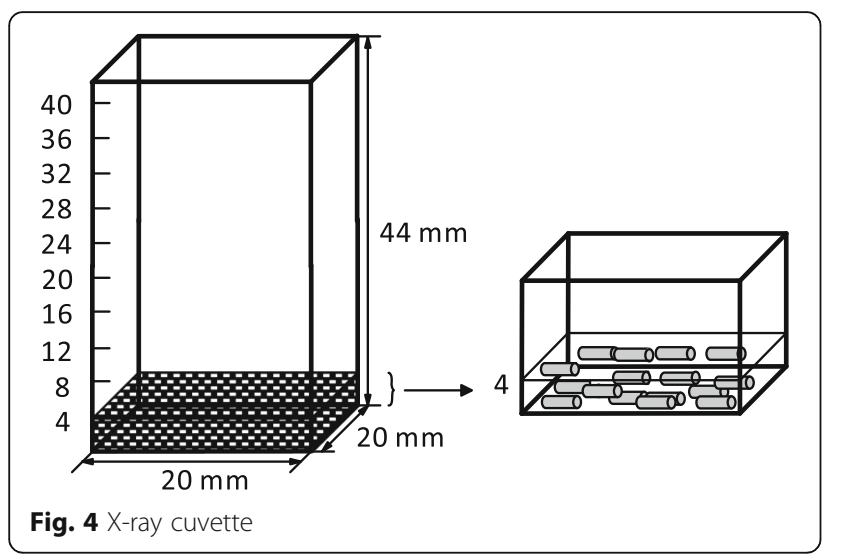

indicating the sample thickness " $x$ " (in $\mathrm{mm}$ ). A thickness step " $\Delta \mathrm{x}$ " of $4 \mathrm{~mm}$ was considered.

The X-ray cuvette was prepared to perform X-ray radiographies at different conditions in order to optimize the technique considering the optimum thickness and energy to be applied. All experiments were performed using the form of package displayed in Fig. 4, as the attenuation process is mainly induced by the adsorbed organic compounds on the GAC. The structural form of the GAC has no direct influence on the measurement results (rods, crushed or pulverized activated carbon); only the chemical characteristics of adsorbed organic compounds determines the photon attenuation. The free space between the particles can be considered as constant, regardless the packing (Crespo Sariol et al. $2017 \mathrm{~b}$ ), in terms of bed porosity being equal to the ratio of free space volume and the total volume of the GAC sample (around 40\%). Between experiments, the same shape of cuvette needs to be applied. The experimental set-up is presented in (Fig. 5). The X-ray cuvette (1) is placed under the X-ray apparatus (2) to be exposed at the X-ray radiation beam. The incident photons are attenuated in the GAC sample. The attenuated photons are registered in a photosensitive material (sensor) (3), and the registered intensity of attenuated

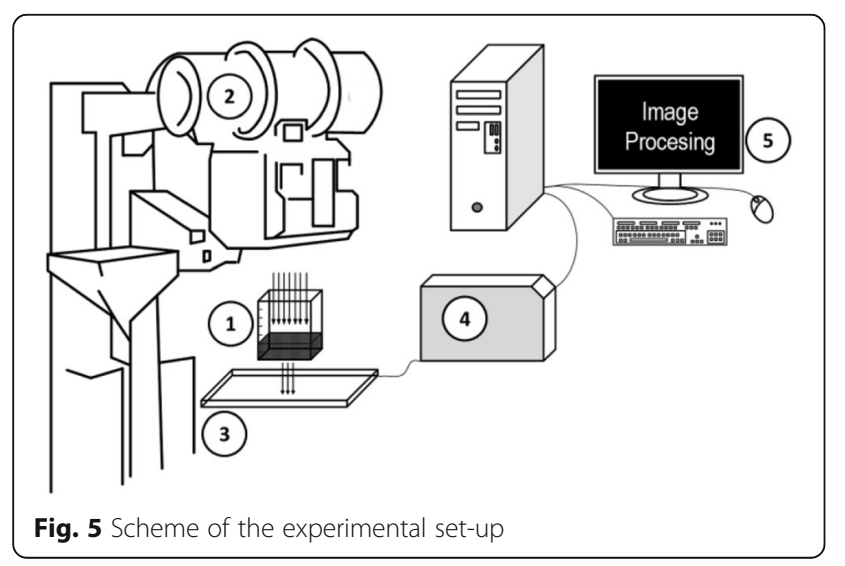

photons is transformed in a grey-scale image using the conversion unit (4).

The more the photons attenuated, the whiter is the grey-scale digital image obtained; in contrast, a darker digital image means less attenuated photons. In other words, a material of low density and atomic number (poor photons absorption/attenuation) will produce a dark image and another material with high-photon attenuation (high density and atomic number), a white image. Finally, the grey scale image is conveniently processed by PC (5) using the MATLAB tool box for digital images processing.

\section{Data processing of $X$-ray images}

The X-ray image histograms of total pixels in a specific intensity level expressed in grey scale were obtained automatically using the MATLAB ${ }^{\circ}$ tool box which is based on the Eq. (3).

$$
h\left(r_{k}\right)=n_{k}
$$

where

$r_{k}$ : normalized grey scale intensity level in the discreet interval of $[0 ; 1] \therefore$ [black; white]

$n_{k}$ : number of pixels at the $r_{k}$ grey scale intensity.

The frequency-amplitude spectrum of the X-ray images were determined using the fast Fourier transform in two dimensions (FFT2) which has as basis the discreet equation presented in (4). FFT2 is also implemented in the MATLAB ${ }^{\circ}$ tool box.

$$
F(p, q)=\sum_{m=0}^{M-1} \sum_{n=0}^{N-1} f(m, n) e^{-j\left(\frac{2 \pi}{M}\right) p m} e^{-j\left(\frac{2 \pi}{N}\right) q n}
$$

where

$f(m, n)$ : Intensity value in the image coordinates $m, n$. $F(p, q)$ : Fourier transforms coefficients off $f(m, n)$.

$M$ : Total number of rows in the image.

$N$ : Total number of columns in the image.

being

$p=0,1,2 \ldots, M-1 ; q=0,1,2 \ldots, N-1$, with $p, q$ discrete spatial frequencies.

The X-ray images of the exhausted GAC are featured with typical white spots. These white spots can be produced due to some foreign matter such as: little chips of wood, small fabric pieces or sand grains (a layer of special sand is placed at the bottom of the rum filter in order to retain the GAC). However, the white spots are also produced by the randomly superposition of GAC exhausted grains, irregularities in the carbon surface and the angle of incidence of the photons on a specific individual GAC grain in the sample, thus producing that interference in the image. A Gaussian low-pass filter was used in order to digitally eliminate this kind of interferences during the experiments. 
The values of the Kernel matrix (filter mask) (Gonzales et al. 2004; Gonzales and Woods 2002) used by the Gaussian filter, are calculated using the Eqs. (5) and (6).

$$
\begin{aligned}
& h_{g}\left(n_{1}, n_{2}\right)=e^{\frac{-\left(n_{1}^{2}+n_{2}^{2}\right)}{2 \sigma^{2}}} \\
& h\left(n_{1}, n_{2}\right)=\frac{h_{g}\left(n_{1}, n_{2}\right)}{\sum_{n_{1}} \sum_{n 2} h_{g}}
\end{aligned}
$$

where

$n_{1}, n_{2}$ : filter mask values.

$\sigma$ : standard deviation.

The linear filtering of a digital image of " $\mathrm{M} x \mathrm{~N}$ " (rows and columns) with a filter mask of " $\mathrm{m} \times \mathrm{n}$ " can be implemented by using Eqs. (7) and (8). The software code used for filtering operations was also implemented in the MATLAB ${ }^{\oplus}$ image processing tool box.

$$
g(x, y)=\sum_{s=-a}^{a} \sum_{t=-b}^{b} w(s, t) f(x+s, y+t)
$$

with

$$
a=\frac{m-1}{2} \text { and } \quad b=\frac{n-1}{2}
$$

where

$g(x, y)$ : filtering operation function of the $f(x, y)$ original image.

$w(s, t)$ : filter mask matrix.

$m$ : number of rows in the filter mask.

$n$ : number of columns in the filter mask.

The complete filtering operation on the entire image is guaranteed for following: $x=0,1,2 \ldots, M-1 ; y=0,1$, $2 \ldots, N-1$. The implemented Gaussian filter uses a square Kernel matrix of eight rows and eight columns with a standard deviation $\sigma=2$. It is generally recommended that the size of the filter mask has to be three to five times the sigma $(\sigma)$ value (Gonzales et al. 2004; Gonzales and Woods 2002; Semmlow 2004).

\section{Relationship between grey-scale intensity and attenuated photonic intensity of the $X$-ray image radiography}

The attenuated photons intensity $(N)$ has a direct equivalent in the grey-scale intensity (GSI) values in the $\mathrm{X}$-ray radiographic image according to the previous description in "Data processing of X-ray images" section. Therefore, it is possible to establish a direct relationship between the photon intensity which reaches the photosensitive material and the grey-scale-formed image. This correlation can be mathematically expressed using Eq. (9).

$$
\mathrm{GSI}=f(N)
$$

where
GSI: grey-scale intensity.

$N$ : attenuated photonic intensity.

Equation (9) expresses the grey-scale intensity (GSI) as function of the attenuated photonic intensity (N). According to Eq. (2), the initial photonic intensity $\left(N_{0}\right)$ and attenuated photonic intensity $(N)$ are exponentially correlated. According to Eq. (9), it is possible to express GSI as an equivalent exponential function of the initial grey-scale intensity $\left(\mathrm{GSI}_{0}\right)$ using the Eq. (10).

$$
\mathrm{GSI}=\mathrm{GSI}_{0} \cdot \mathrm{e}^{(\mu \cdot \mathrm{x})}
$$

where

GSI: grey-scale intensity of attenuated photons (in grey-scale levels).

$\mathrm{GSI}_{0}$ : grey-scale intensity of incident photons (in grey-scale levels).

The grey-scale intensity of incident photons $\left(\mathrm{GSI}_{0}\right)$ was calculated by performing $\mathrm{X}$-ray radiographies at empty X-ray cuvette (without GAC sample). The GSI at $125 \mathrm{mAs}$ and $22 \mathrm{keV}$ was approximately 0.0039 (22 keV/ $125 \mathrm{mAs}$ was the optimum value of energy for performing the experiments). At empty X-ray cuvette, GSI = $\mathrm{GSI}_{0}$, thus derived from Eq. 10, $\mu=0$.

\section{Results and discussion}

Figure 6 depicts the original X-ray radiography images of samples of GAC-virgin (a) and GAC-Top "exhausted" (b). By a quick inspection to Fig. 6, differences in the grey-scale brightness between samples can be seen. The GAC-virgin presents more concentration of dark zones than the exhausted GAC. The dark zones are related with less attenuated photons in the sample (less photonic absorption). In contrast, the GAC-Top presents more clear zones indicating an increment in the attenuated photons, thus more absorbed photons. As the Xphotons attenuation increases with the density of the material, the adsorbed organic substances in the exhausted GAC can absorb more photons producing a whither image.

The fact that the GAC-Top is saturated with different organic substances has been demonstrated using different analytical techniques which have been discussed in detail in Crespo Sariol et al. (2016b, 2016a, 2016c, 2017b, 2017a). The red arrow in Fig. $6 \mathrm{~b}$ is indicating one white spot which nature was previously described in the "Data processing of X-ray images" section.

Figure 7 shows the amplitude and frequency spectrums of the X-ray radiography images of GAC-virgin (a) and GAC-Top "exhausted" (b) in correspondence with Fig. 6a, b.

The observed peaks (more noticeable in GAC-Top with evident more amplitude than in the case of GACvirgin) are the direct component of the image. These 


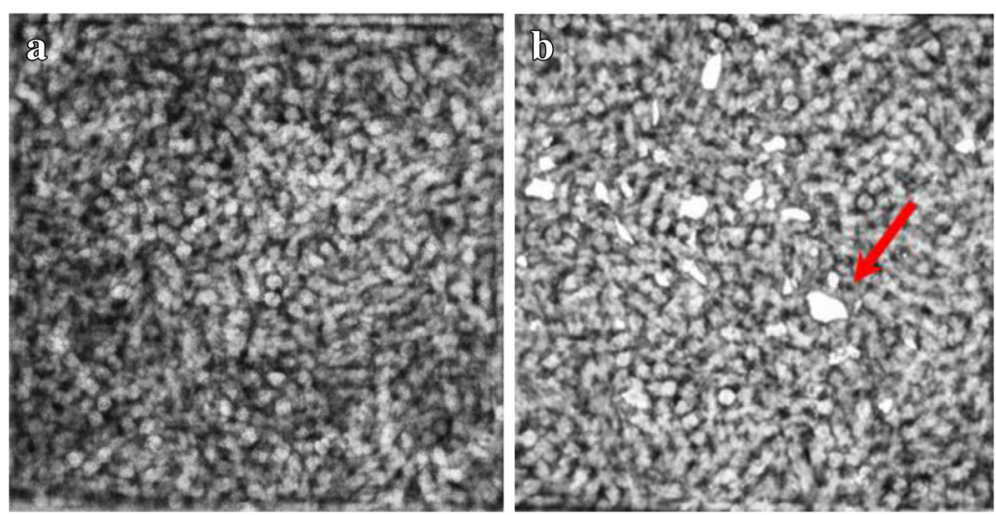

Fig. 6 Digital X-ray radiography images of samples of GAC-virgin $\mathbf{a}$ and GAC-Top "exhausted" $\mathbf{b}$ before and after use in a rum production process. Energy: $22 \mathrm{keV}-125 \mathrm{mAs}$, sample thickness (x): $12 \mathrm{~mm}$

peaks represent the sum of the intensity levels of each pixel in the image for spatial frequency equal to zero $(q=p=0$, Eq. (4)). As the image obtained for the GACTop presents pixels in the grey-scale with more intensity (near to one in the grey scale/more clear zones) than in the case of the GAC-virgin, the amplitude peak of the direct component of GAC-Top is higher than the amplitude peak observed in the GAC-virgin which have pixels of less intensity (near to zero in the grey scale/ more dark zones).This is the first evidence of exhaustion condition of the GAC based on X-ray radiography images processing.

According to Eqs. (2) and (10), the number of attenuated photons $(N)$ that defines the obtained grey-scale intensity (GSI) depends on the initial intensity, the linear absorption coefficient and the sample thickness. In our case, the characterization of the exhaustion level is based on the comparison of the GSI as a parameter and the characteristics of the X-ray radiography images. Therefore, in order to obtain useful results with a proper GSI to be compared, the initial intensity and the sample thickness must be optimized for the proposed X-ray radiography method. The linear absorption coefficient depends on the nature of the material, thus a constant value (discussed later).
The optimization of the parameters $N_{0}$ and $x$ for the X-ray radiography method was conducted basically under the principle that the better condition to perform the method is to find the proper intensity and sample thickness combination that permits to obtain a maximum in the differences between the extreme samples GAC-virgin and most exhausted (GAC-Top). Finding this optimum using these extremes, even the smaller differences in the exhaustion degree between other two GAC samples can be detected, thus increasing the sensitivity of the proposed method.

Following the optimum strategy, three energies were explored: $22 \mathrm{keV}-125 \mathrm{mAs}, 30 \mathrm{keV}-125 \mathrm{mAs}$ and $40 \mathrm{keV}-4 \mathrm{mAs}$. For each level of energy, different sample thickness " $x$ " were evaluated from 0 to $40 \mathrm{~mm}$ (step $4 \mathrm{~mm}$ ) according to the X-ray cuvette characteristics described in the "Data processing of X-ray images" section.

Tables 1 and 2 present the grey-scale intensity (GSI) of the X-ray digital radiography images for the GAC-Top and GAC-virgin at different energies and thickness combinations. At sample thickness $x=0$ (empty X-ray cuvette), the GSI $=\mathrm{GSI}_{0}$ and the obtained value was 0.0039 for all the explored energies. Theoretically, as in the grey-scale, the discreet interval of $[0 ; 1]$ is translated as a [black; white] interval, without sample the

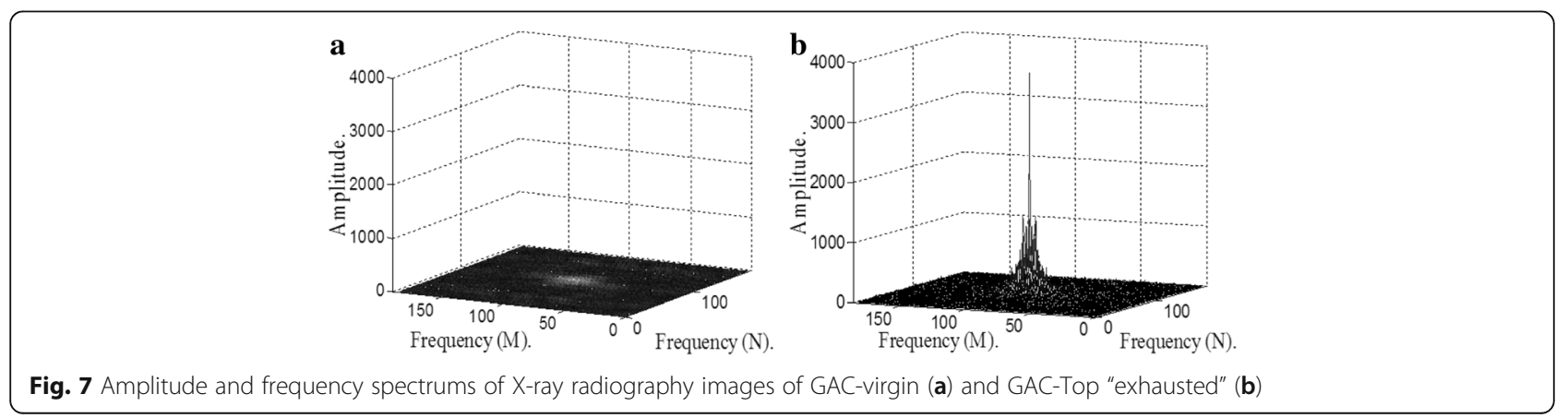


Table 1 Grey-scale intensity (GSI) of the X-ray radiography images for the GAC-Top and GAC-virgin at 22 keV-125 mAs and 30 keV-125 mAs

\begin{tabular}{|c|c|c|c|c|c|c|c|c|}
\hline \multirow{2}{*}{$\begin{array}{l}x \\
(\mathrm{~mm})\end{array}$} & \multicolumn{4}{|c|}{$22 \mathrm{keV}-125 \mathrm{mAs}$} & \multicolumn{4}{|c|}{$30 \mathrm{keV}-125 \mathrm{mAs}$} \\
\hline & GAC-virgin & $\sigma(\mathrm{GSI})$ & GAC-Top & $\sigma(\mathrm{GSI})$ & GAC-virgin & $\sigma(G S I)$ & GAC-Top & $\sigma(G S I)$ \\
\hline 0 & 0.0039 & 0 & 0.0039 & 0 & 0.0039 & 0 & 0.0039 & 0 \\
\hline 4 & 0.0039 & 0 & 0.0039 & 0 & 0.0039 & 0 & 0.0039 & 0 \\
\hline 8 & 0.3711 & 0.0022 & 0.6055 & 0.0042 & 0.37 & 0.0022 & 0.45 & 0.0023 \\
\hline 12 & 0.3516 & 0.0022 & 1 & 0 & 0.29 & 0.0072 & 0.46 & 0.0023 \\
\hline 16 & 0.6211 & 0.0088 & 1 & 0 & 0.5424 & 0.0059 & 0.8 & 0.021 \\
\hline 20 & 1 & 0 & 1 & 0 & 0.945 & 0.024 & 1 & 0 \\
\hline 24 & 1 & 0 & 1 & 0 & 1 & 0 & 1 & 0 \\
\hline 28 & 1 & 0 & 1 & 0 & 1 & 0 & 1 & 0 \\
\hline 32 & 1 & 0 & 1 & 0 & 1 & 0 & 1 & 0 \\
\hline 36 & 1 & 0 & 1 & 0 & 1 & 0 & 1 & 0 \\
\hline 40 & 1 & 0 & 1 & 0 & 1 & 0 & 1 & 0 \\
\hline
\end{tabular}

image must be totally black (GSI $=0)$. Nevertheless, the error of 0.0039 observed is constant for all the experiments therefore no effect on the final results.

Five independent radiographies in each case were performed. A normal distribution for the results was obtained. The averaged value of the GSI for each sample is presented in Tables 1 and 2. The multiple comparison method was applied to determine statistical differences between the mean of the samples. The applied method was the Fisher's lower significant difference (LSD) method.

When the sample thickness increases, GSI for all GAC samples becomes equal to 1 , except for the $40 \mathrm{keV}-4 \mathrm{mAs}$ experiments. The thicker the sample is, the more attenuated photons and the whiter the X-ray radiography. According to Table 1 , at $22 \mathrm{keV}-125 \mathrm{mAs}$ of energy, a statistically white image is already obtained at $12 \mathrm{~mm}$ for the GAC-Top and at $20 \mathrm{~mm}$ for the GAC-virgin. This result is in line with the exhausted condition of the GAC-Top. The white image appears at less thickness

Table 2 Grey-scale intensity (GSI) of the X-ray radiography images for the GAC-Top and GAC-virgin at $40 \mathrm{keV}-4 \mathrm{mAs}$

\begin{tabular}{lllll}
\hline$x$ & $40 \mathrm{keV}-4 \mathrm{mAs}$ & & & \\
\cline { 2 - 5 }$(\mathrm{mm})$ & GAC-virgin & $\sigma(\mathrm{GSI})$ & GAC-Top & $\sigma(\mathrm{GSI})$ \\
\hline 0 & 0.0039 & 0 & 0.0039 & 0 \\
4 & 0.0039 & 0 & 0.0039 & 0 \\
8 & 0.0898 & 0.0079 & 0.0898 & 0.0079 \\
12 & 0.0859 & 0.0075 & 0.1016 & 0.0123 \\
16 & 0.1406 & 0.0170 & 0.1914 & 0.0035 \\
20 & 0.1367 & 0.0101 & 0.1714 & 0.0035 \\
24 & 0.1445 & 0.0170 & 0.2305 & 0.0043 \\
28 & 0.2109 & 0.0052 & 0.2773 & 0.0061 \\
32 & 0.2704 & 0.0061 & 0.3205 & 0.0012 \\
36 & 0.4248 & 0.0031 & 0.4321 & 0.0035 \\
40 & 0.4955 & 0.0053 & 0.1016 & 0.0073 \\
\hline
\end{tabular}

of the exhausted carbon due to the high concentration of adsorbed compounds onto this GAC producing a more intense photonic attenuation effect. At $30 \mathrm{keV}-125 \mathrm{mAs}$, the statistically white image is obtained at $20 \mathrm{~mm}$ for the GAC-Top and at $24 \mathrm{~mm}$ for the GAC-virgin. An increment of the energy produces a displacement in the sample thickness before reaching the white image. The penetration power increases; therefore, the thickness of sample for attenuating the photons must be larger. This phenomenon is clearly observed at $40 \mathrm{keV}-4 \mathrm{mAs}$. In this case, the sample size is insufficient to obtain a statistically white X-ray image; an increment in the penetration power of the X-photons occurred and thus causes a lower photonic attenuation. Therefore, this energy or higher values is of no practical use. The fact that the registered values for GSI as a function of the thickness for the GAC-virgin sample experiment does not follow a regular increasing tendency (for $22 \mathrm{keV}$ and $30 \mathrm{keV}$ at 8 and $12 \mathrm{~mm}$, for $40 \mathrm{keV}$ at 8 and $12 \mathrm{~mm}$ and 16 and $20 \mathrm{~mm}$ ) deals with Eq. 10 , where an exponential behaviour is followed.

In order to optimize the values of energy and sample thickness to get a proper sensitivity for the X-ray method, a maximum in the differences of the grey-scale intensity (DGS) between the extreme samples has to be calculated. According the obtained values of GSI (Tables 1 and 2), a difference between the GSI of the extreme samples can be determined by the DSG function as it is presented in Eq. (11).

$$
\mathrm{DGS}=\mathrm{GSI}_{\mathrm{Top}}-\mathrm{GSI}_{\mathrm{virgin}}
$$

where:

DSG: difference in the grey-scale intensity.

GSI $_{\text {Top: }}$ grey-scale intensity of the GAC-Top

GSI $_{\text {virgin }}$ : grey-scale intensity of the GAC-virgin

Figure 8 depicts the DGS values at different energies and sample thickness. 


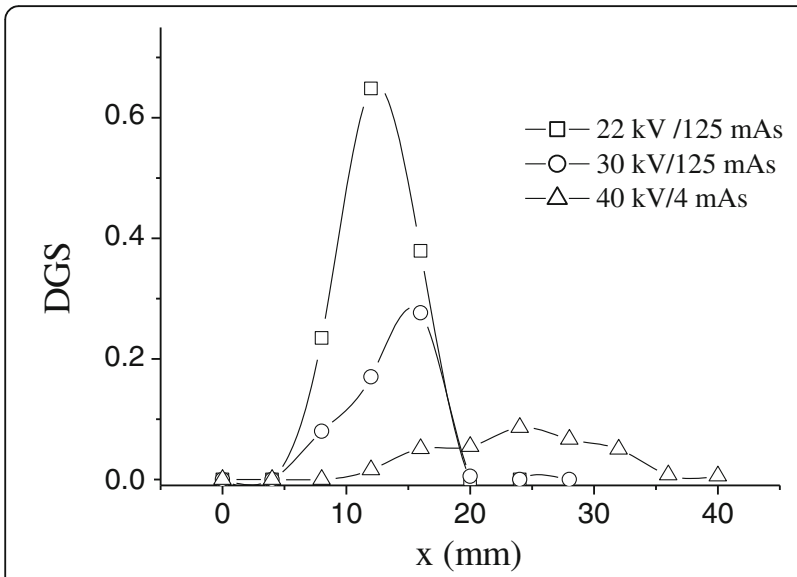

Fig. 8 Differences in the grey-scale intensities (DGS) obtained for the extreme samples GAC-virgin and GAC-Top (exhausted) DGS

DGS values were calculated from Tables 1 and 2. According to Fig. 8, maximum peaks in the DGS were found at all the explored energies but with different amplitude and different values of sample thickness. The highest peak was obtained at $22 \mathrm{keV}-125 \mathrm{mAs}$ and $12 \mathrm{~mm}$ of sample thickness, with a DGS value around 0.65. The higher the energy applied, the lower the DGS peak amplitude and the larger the sample thickness. In the case of 30 and $40 \mathrm{keV}$, peaks at around 0.3 and 0.08 were observed, respectively. Additionally, sample thickness of 16 and $24 \mathrm{~mm}$ were needed. According to this behavior, we can conclude that the higher the energy applied, the larger the amount of GAC is needed and the less sensitivity for detecting sample differences. Based on the abovementioned, the proper experimental condition to perform the X-ray radiography of the GAC samples was $22 \mathrm{keV}$ $125 \mathrm{mAs}$ of energy and GAC thickness of $12 \mathrm{~mm}$.

Table 3 presents the grey-scale intensity and linear absorption coefficient for different GAC layers and for the GAC-virgin. X-ray radiographic images were performed at optimal conditions of $22 \mathrm{keV}-125 \mathrm{mAs}$ and sample thickness of $12 \mathrm{~mm}$.

Although evident differences between GAC-Top and GAC-virgin can be observed in terms of $\overline{\mathrm{GSI}}$ and the linear absorption coefficient $(\mu)$, no significant statistical differences in the $\overline{\text { GSI }}$ and $\mu$ values for comparing the exhaustion level at different GAC layers in the rum filter were found. The plot of the linear absorption coefficient at different GAC layers in the rum filter and the GACvirgin is presented in Fig. 9. The multiple comparison method was applied to determine statistical differences between the mean of the samples using Fisher's lower significant difference (LSD) method. For the GACvirgin, the lowest linear absorption coefficient of $0.241 \mathrm{~mm}^{-1}$ was obtained which is consistent with its unused quality thus poor photon attenuation. In contrast, the GAC samples from the rum filter present a constant linear absorption coefficient with about $0.37 \mathrm{~mm}^{-1}$; this value corresponds with the adsorbed compounds on the GAC surface after being used in rum production. The linear absorption coefficient depends on the nature of the adsorbed substance; therefore, the almost constant value of $\mu$ is suggesting that similar families of key-components, which are X-ray sensitive, are adsorbed on the carbon surface in all the GAC layers in the rum filter. This was previously reported in Crespo Sariol et al. (2017b, 2017a) where the same predominant families of fatty esters were detected by TD-GC/MS in all the GAC layers but at different relative abundance.

The invariability of $\mu$ also suggests that there are not noticeable differences of density in the GAC layers. As a consequence, the use of the method supported by GSI differences does not give in this way an added value in determining differences between GAC samples. Therefore, the spatial concentration concept is introduced as an alternative to the $\overline{\text { GSI }}$ comparison. Using the spatial concentration, the abundance of pixels at the same GSI can be quantified; therefore, the abundance of the key compounds in the GAC which produce this GSI and saturate the carbon can be also determined. Figure 10 shows the filtered image histogram of the GAC-virgin (a), GAC-Top (b) and GAC-Bottom (c). The grey-scale intensity in the case of GAC-virgin (a) is nearly 0.1 , with a defined peak. This GSI level is a direct consequence of the chemical and physical characteristics of the GAC-virgin which mostly coincided with low atomic number $(Z)$ elements practically transparent $(\mathrm{GSI} \approx 0)$ to $\mathrm{X}$-ray radiation, producing a predominant black image due to a low photonic attenuation. The GSI distribution in GAC-Bottom (c) and GAC-Top (b) is definite broader than the GSI distribution for the GAC-virgin. The range of GSI distribution for GAC-Top (b) demonstrates a broad peak around 0.35 indicating the different nature of this GAC sample.

Table 3 Grey-scale intensity and linear absorption coefficient at different GAC layers and GAC-virgin (22 keV-125 mAs)

\begin{tabular}{llllllllll}
\hline GAC layer & Top $(0)$ & 0.2 & 0.4 & 0.6 & 0.8 & 1.0 & 1.3 & Bottom (1.5) & GAC-virgin \\
\hline$\overline{\text { GSI }}$ & 0.322 & 0.360 & 0.345 & 0.400 & 0.333 & 0.357 & 0.313 & 0.259 & 0.0703 \\
$\mu$ & 0.368 & 0.377 & 0.373 & 0.385 & 0.370 & 0.376 & 0.365 & 0.349 & 0.241 \\
$\sigma(\overline{G S I})$ & 0.022 & 0.023 & 0.022 & 0.023 & 0.022 & 0.019 & 0.021 & 0.020 & 0.014 \\
\hline
\end{tabular}

The linear absorption coefficient $\mu$ was calculated using Eq. (10) with $\mathrm{GSI}_{0}=0.0039$

$\overline{G S I}$ mean of grey-scale intensity values for five independent experiments, $\sigma(\overline{G S I})$ standard deviation 


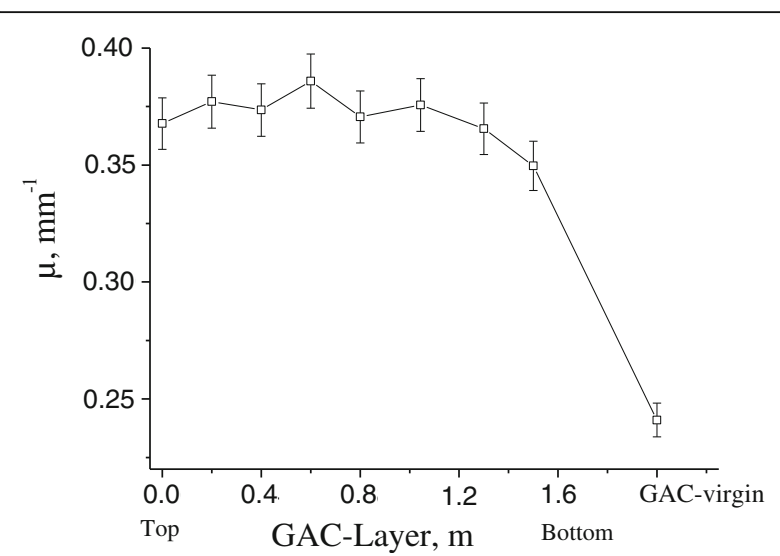

Fig. 9 Plot of the linear absorption coefficient $(\mu)$ at different GAC layers in the rum filter and the GAC-virgin

The predominant substance in the GAC-virgin is just carbon producing a dark image; however, in the case of GAC-Top-adsorbed compounds produce an image with a quite different grey-scale pattern. In the case of GACbottom (Fig. 10c), the image histogram has similar behavior in comparison with GAC-Top. Both are featured by a broader peak located in a similar region of GSI. However, the GAC-Bottom peak is displaced to the left, indicating a darkening of the image pointing to the GAC-virgin-like characteristics giving evidence of a less exhaustion level in comparison with the GAC-Top. Based on these histograms, in terms of total pixels at the maximum, a comparison can be made pointing to the nature and the amount of adsorbed organic compounds.

Indeed it is found that the GSI value in the histogram is consistent with a determinate combination of chemical compounds, which in dependence of the atomic weight can cause more or less photonic attenuation changing the GSI value in the grey-scale. The approximate amount of a determinate combination of chemicaladsorbed compounds is better given by the spatial concentration $\left(\mathrm{S}_{\mathrm{C}}\right)$ concept. It is found that similar GSI levels (indicating that the adsorbed compounds have the same chemical nature) give different $S_{C}$ (indicating different amount of compounds with the same chemical nature). The previous analysis was fundamental to properly correlate the $S_{C}$ with the TD-GC/MS analysis and the exhaustion degree in the rum filter, rather than the sum of pixels over the normalized grey scale. Using a low pass filtering of the image, all the pixels in the normalized grey-scale are modified. However, the filtering of the image is very useful to digitally eliminate the impurities effect in the image and rebound the zones of greater pixels concentration. But, it also modified the other pixels in the image. In this context, the sum of the pixels in the grey-scale is therefore a not trustable method. Based on Eq. (3), the spatial concentration $S_{C}$

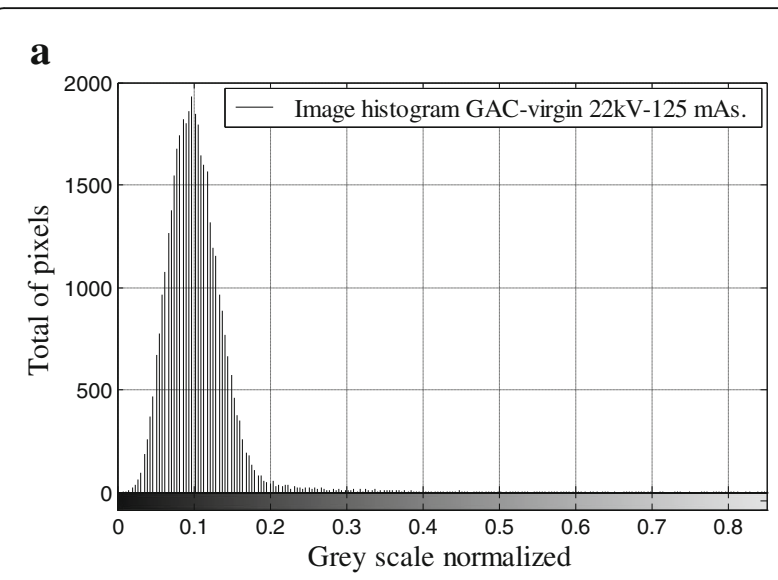

b

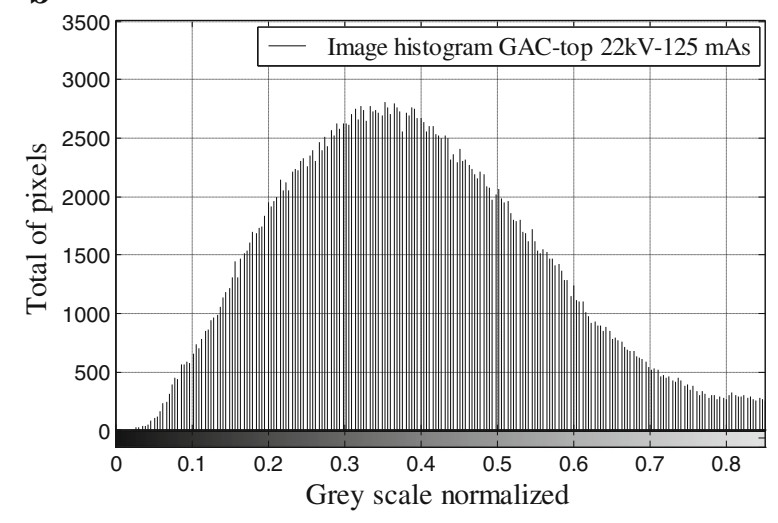

c

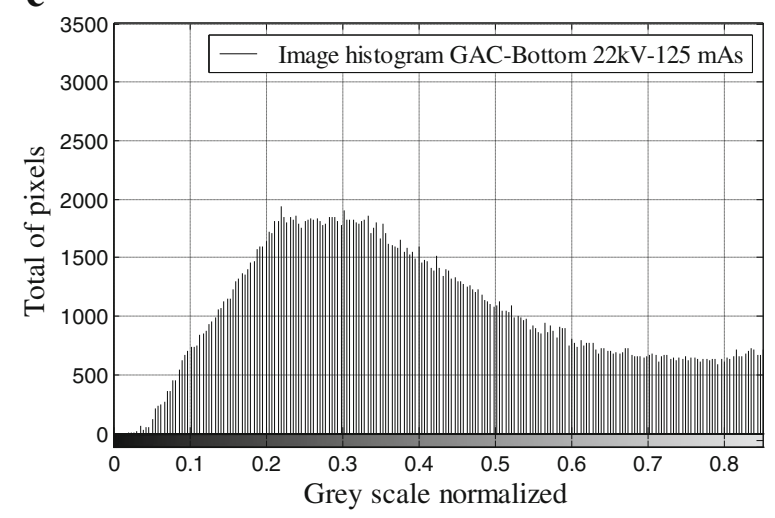

Fig. 10 Image histograms of the GAC-virgin (a), GAC-Top (b) and GAC-Bottom (c)

(in pixel), for a specific GSI, can be related with the normalized grey-scale value when the total of pixels maximizes, i.e. $\mathrm{T}_{\mathrm{P}}(\mathrm{GSI})$ and can be expressed by Eq. (12).

$$
\mathrm{S}_{\mathrm{C}}(\mathrm{GSI})=\mathrm{T}_{\mathrm{P}}(\mathrm{GSI})
$$

where:

$\mathrm{T}_{\mathrm{P}}(\mathrm{GSI})$ : total of pixels corresponding to GSI. 
$\mathrm{S}_{\mathrm{C}}(\mathrm{GSI})$ : spatial concentration of the intensity level GSI (in pixel).

Then, the spatial concentration can be used to characterize the abundance of adsorbed organic compounds on the GAC surface, thus the exhaustion level of the GAC samples in the rum filter. The spatial concentration $\mathrm{S}_{\mathrm{C}}$ (GSI) was calculated based on the GSI distribution in the image histogram. As the GAC-Top is the most exhausted sample, its GSI $=0.35$ at the peak distribution was taken as reference to be compared with the other samples.

Table 4 depicts the spatial concentration values at different GAC layers in the rum filter taking the GAC-Top as GSI reference.

The spatial concentration of pixels related with the GSI of reference decreases from the top to the filter's bottom. This is in correspondence with the exhaustion level in the industrial rum filter discussed based on different analytical methods presented in Crespo Sariol et al. (2017b; 2017a).

Figure 11 shows the GAC exhaustion profile in the rum filter based on the spatial concentration analysis of $\mathrm{X}$-ray radiography digital image processing.

The exhaustion profile by the X-ray method is in line with results reported in Crespo Sariol et al. (2017b, 2017a) where almost the same exhaustion pattern was obtained applying other methods such as TGA, acoustic emission, NMR, TD-GC/MS, CHNS-O elemental analysis, colorimetry and immersion bubblemetry. In contrast, sample 1.3 does no show that special behavior as found for the other techniques. This can be explained as follows: X-ray radiography technique explores the volumetric behavior of GAC, taking advantage of the different photonic attenuation in correspondence with the total amount of adsorbed organic compounds in the sample, thus is not oriented to the determination of the porous characteristics of the GAC like the other techniques. The idea of using this technique as a fast and reliable method to characterize the exhaustion degree of porous materials is that it does not require any extensive sample preparation, like drying or pulverizing process as in the other techniques.

Based on the TD-GC/MS results presented in Crespo Sariol et al. (2017b, 2017a), for all the studied GAC samples, the same predominant family of compounds (fatty esters and phenolics) were found in all the GAC-layers

Table 4 Spatial concentration values at different GAC layers in the rum filter

\begin{tabular}{lllllllll}
\hline GAC layer & Top $(0)$ & 0.2 & 0.4 & 0.6 & 0.8 & 1.0 & 1.3 & Bottom (1.5) \\
\hline$\overline{S_{C}(0.35)}$ & 2804 & 2472 & 2400 & 2256 & 2200 & 2100 & 2100 & 1700 \\
$\sigma(S c)$ & 84 & 74 & 72 & 68 & 66 & 63 & 64 & 51 \\
\hline \hline
\end{tabular}

$\overline{S_{C}}$ mean of spatial concentration values for five independent experiments and $\sigma(S c)$ standard deviation

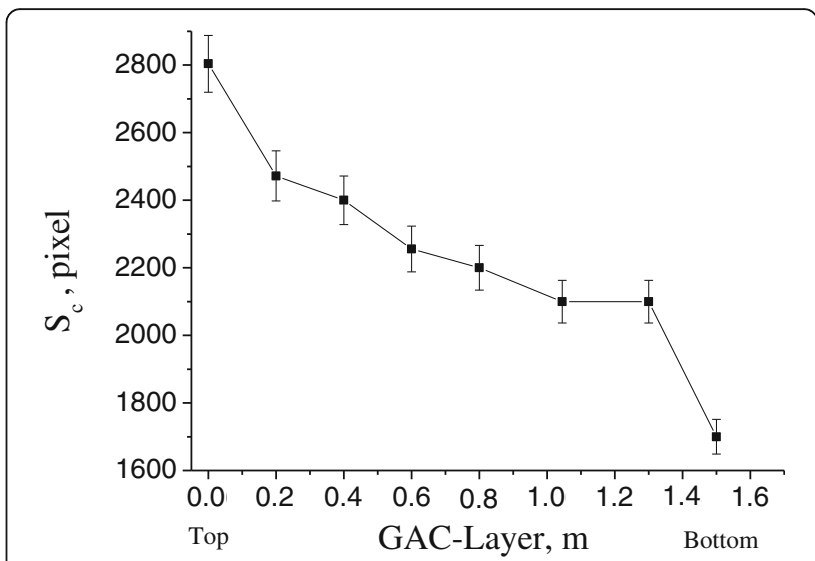

Fig. 11 GAC exhaustion profile in the rum filter based on the spatial concentration analysis of $\mathrm{X}$-ray radiography digital image processing

but with different relative abundance. Figure 12 depicts the TD-GC/MS chromatograms of the different GAC samples in the rum filter.

Table 5 presents the abundant organic compounds detected in the rum filter GAC by TD-GC/MS analysis.

The GAC-Top showed the highest concentration of adsorbed compounds with the highest signal intensity. The evolution of the sum of the peak areas decreased from the top to the bottom reaching the lowest value for GAC-bottom. The relative area under the chromatographic TD-(GC/MS) signal was calculated for the abundant organic compounds. Results were averaged for each family.

Figure 13 depicts the relation plot between Sc and the relative area under the TD-GC/MS chromatographic signal for the fatty esters family.

If GAC-bottom image histogram (Fig. 10c) is analyzed, it is noticeable that GAC-bottom histogram is slightly displaced to the left of 0.35 which was the GSI selected as reference of comparison to quantify the Sc value in the $\mathrm{X}$-ray radiography images. Actually, the histogram of GAC-bottom is trending to behave like GAC virgin histogram pattern which cannot be considered for comparing with the rest of used samples due to a totally different range in the GSI. The GAC virgin has a very low GSI characteristic value in comparison whit GAC samples in the rum filter. Applying GAC virgin as a reference results in a Sc value approximating zero as a direct consequence of the low pixel concentration of the GAC virgin in this GSI level. GAC virgin is in other words totally not comparable with the used GAC in the rum production process for this technique and therefore cannot be used as the reference as is already noticed. The behavior of GAC-bottom can be interpreted as an evidence of very low exhaustion degree in correspondence with the other samples or/and absence of the majority of key organic components which produce the 


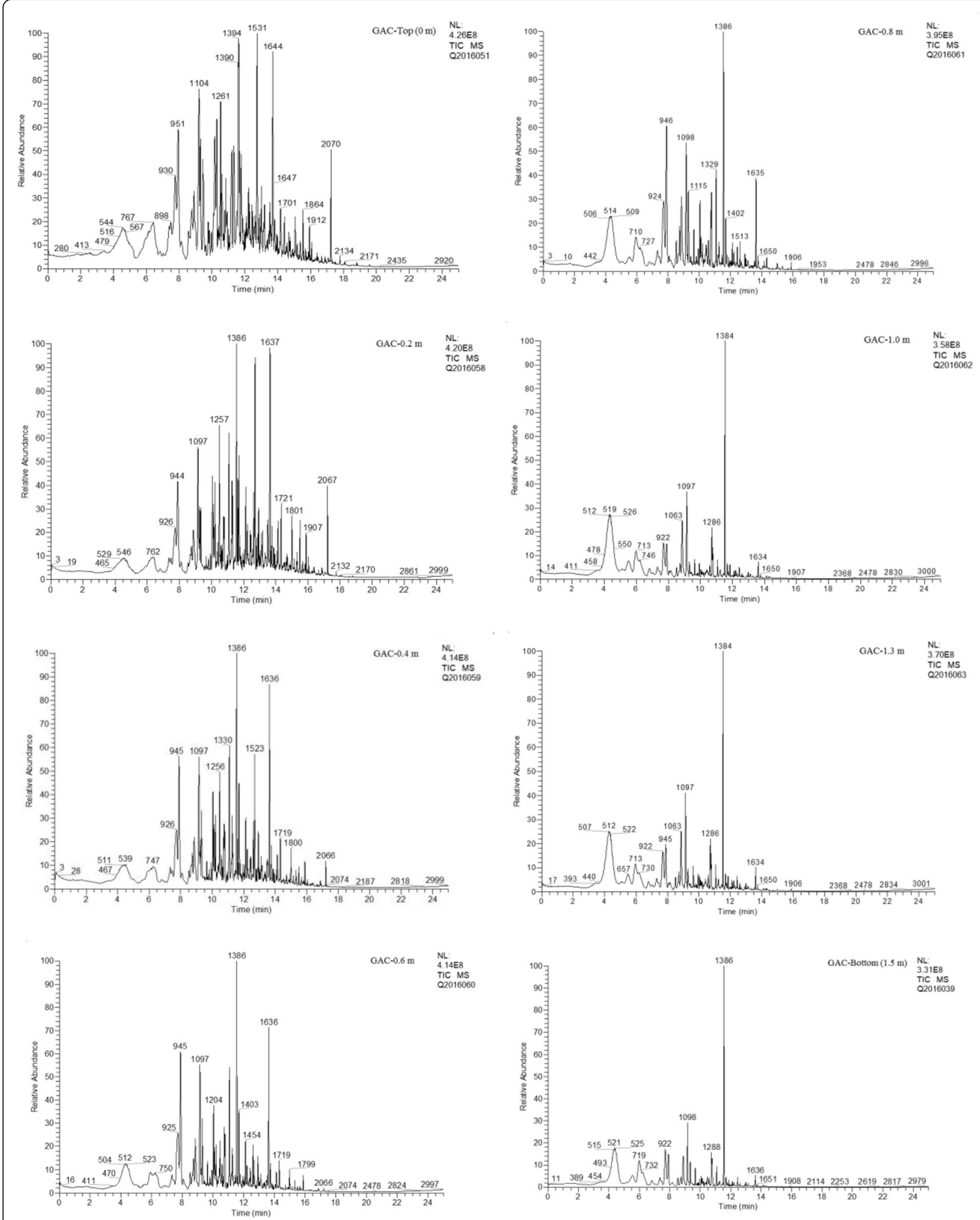

Fig. 12 TD-GC/MS chromatograms of the different GAC samples in the rum filter (adapted from Crespo Sariol et al. (2017b; 2017a)) 
Table 5 Abundant organic compounds detected in the rum filter GAC by TD-GC/MS analysis (adapted from Crespo Sariol et al. (2017a, 2017b))

\begin{tabular}{lll}
\hline Compound & Family & $(\mathrm{m} / \mathrm{z})$ \\
\hline Ethyl decanoate & Fatty ester & $(1384-1394)$ \\
Ethyl hexadecanoate & Fatty ester & $(2066-2070)$ \\
Ethyl dodecanoate & Fatty ester & $(1635-1644)$ \\
Ethyl octanoate & Fatty ester & $(1097-1104)$ \\
2-Methoxyphenol (Guaiacol) & Phenols & $(922-951)$ \\
$\begin{array}{l}\text { 3-Methoxy-4-hydroxy-acetophenone } \\
\text { (acetovanillone) }\end{array}$ & Vanilloids & $(1523-1531)$ \\
\end{tabular}

photonic attenuation. The other two families of abundant organic compounds were explored and also related with Sc. Figure 14 presents the correlation plots for phenols and fatty acids. The higher their concentration on the GAC (the amount adsorbed during the rum production process) the better the global trend line follows the measured data points.

Table 6 shows the fitting correlation parameters found for the different families of adsorbed organic compounds. Based on the presented results showed in Table 6, Figs. 13 and 14, the best regression coefficient $\left(R^{2}\right)$ was found for fatty acids and fatty esters family. The other abundant family (phenols) presented a relative lower fitting goodness, but still acceptable.

Taking into account that the X-ray radiography technique explore the combined effect of the abundant compounds in the rum filter, the obtained data for the TD-GC/MS chromatographic signal for abundant compounds in the rum filter were averaged and related with the obtained Sc values. Figure 15 presents the relation plot for the combined effect of the most abundant organic compounds on the rum filter.

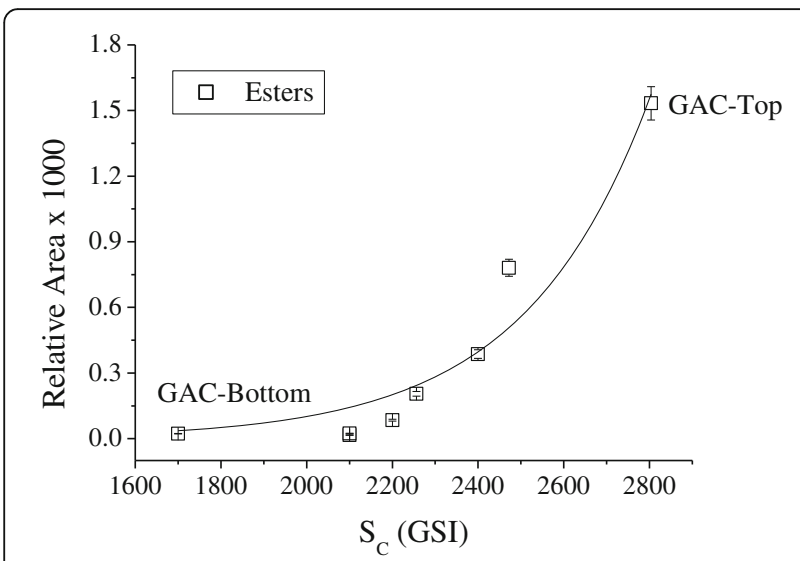

Fig. 13 Relation between Sc and the relative area under the TD-GC/ MS chromatographic signal for esters

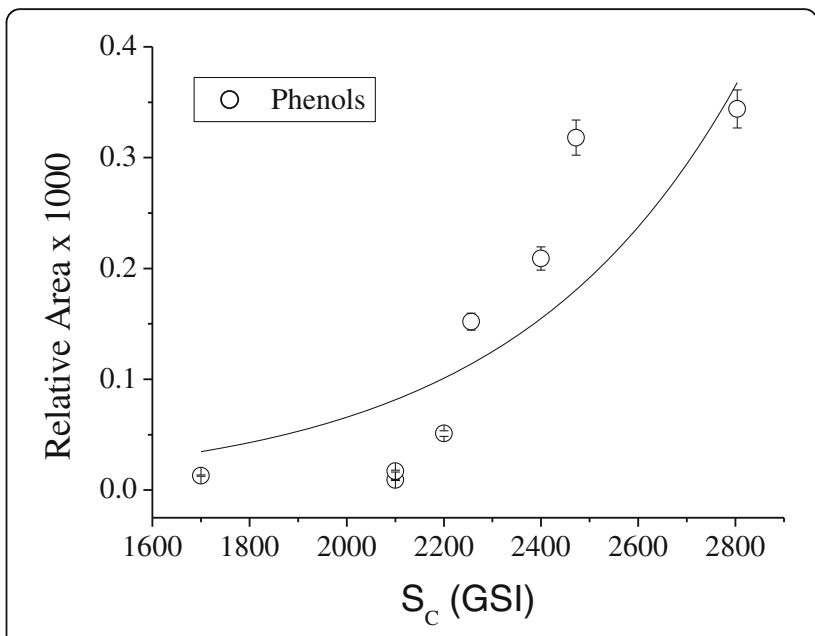

Fig. 14 Relation between SC and the relative area under the TD-GC/ MS chromatographic signal for phenols and fatty acids

Table 7 shows the fitting correlation parameters found for the exponential fitting between Sc and relative area under the TD-GC/MS chromatographic signal for the combined effect of the predominant compounds in the rum filter.

The obtained exponential growth fitting demonstrates clearly the good relation between $\mathrm{Sc}$ and the relative area under the TD-GC/MS chromatographic signal showed in Fig. 15 of the combined effect of the abundant organic compounds adsorbed on the rum filter. This exponential trend is also according to the photonic absorption process. Based on Figs. 13 and 14, one can conclude that the fatty acids are almost all adsorbed at the top of the filter explaining the approximate exponential trend. Fatty esters follow this same tendency but to a lower extend. Phenols present a slightly different adsorption trend, although rather exponential like but evidencing the complexity of the competing adsorption process on the rum filter.

Based on the obtained results, the photon attenuation is mainly a combined effect of the adsorbed organic compounds and also ruled by its relative abundance combinations where the fatty esters and fatty acids family have the highest contribution.

Table 6 Fitting correlation parameters found for the different families of organic compounds

\begin{tabular}{lcllllll}
\hline $\begin{array}{l}\text { Family of } \\
\text { compounds }\end{array}$ & $y_{0}$ & $e\left(y_{0}\right)$ & $A$ & $e(A)$ & $t$ & $e(t)$ & $R^{2}$ \\
\hline Esters & 0 & $( \pm) 0$ & $1.10^{-4}$ & $( \pm) 3.10^{-4}$ & 293 & $( \pm) 1.10^{-3}$ & 0.938 \\
Fatty acids & 0 & $( \pm) 0$ & $5.10^{-5}$ & $( \pm) 7.10^{-5}$ & 253 & $( \pm) 4.10^{-4}$ & 0.992 \\
Phenols & 0 & $( \pm) 0$ & $9.10^{-4}$ & $( \pm) 4.10^{-3}$ & 467 & $( \pm) 1.10^{-3}$ & 0.738 \\
\hline$y=y_{0}+A_{1} e^{\left(x / t_{1}\right)}$ resulting in $y=A e^{(x / t)}$ (with $e(i)$ the error on parameter $\left.i\right)$
\end{tabular}




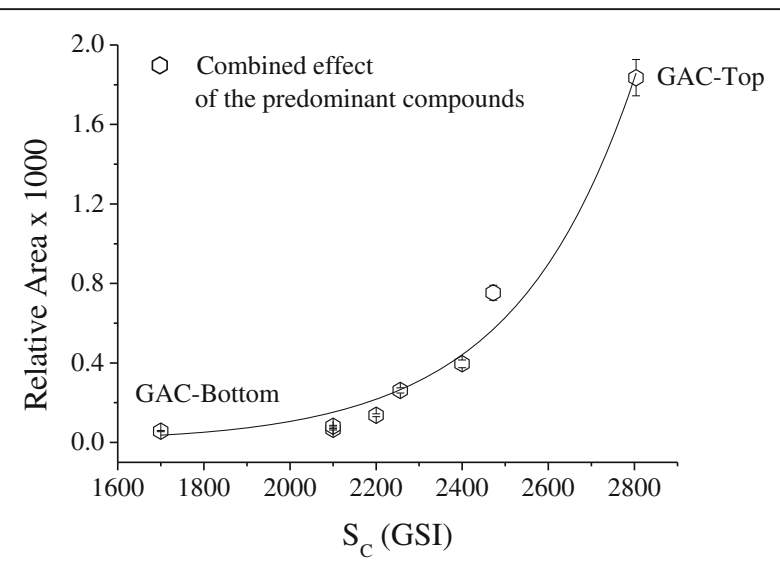

Fig. 15 Relation between Sc and relative area under the TD-GC/MS chromatographic signal for the combined effect of the predominant compounds in the rum filter (Fatty esters, fatty acids and phenols)

\section{Conclusions}

It can be stated that digital image processing by $\mathrm{X}$-ray digital radiography proved to be a suitable and sensitive tool to determine the GAC exhaustion degree. The results can be satisfactory correlated with other methods recently published (Crespo Sariol et al. 2017a, 2017b).

In comparison with the other methods already applied for characterizing the exhaustion level of GAC samples, the digital image processing by X-ray digital radiography method requires no reactants to be performed and allows the digital cleaning of possible samples impurities.

The proposed X-ray radiography-image processing method satisfactory correlates with the TD-GC/MS chromatographic pattern of the GAC exhausted in rum production. The spatial concentration can be exponentially correlated with the relative abundance of some classes of adsorbed organic compounds on the carbon surface.

Although this study is focused on GAC used in rum production, the proposed technique can be applied in the assessment of other adsorption systems such as determining the poisoning level of catalyst material, the GAC exhaustion level in organic polluted water treatments and the GAC regeneration degree and exhaustion studies on hemo-perfusion GAC cartridges.

Table 7 Fitting correlation parameters found for the combined effect of the predominant compounds in the rum filter

\begin{tabular}{llllllll}
\hline $\begin{array}{l}\text { Family of } \\
\text { compounds }\end{array}$ & $y_{0}$ & $e\left(y_{0}\right)$ & $A$ & $e(A)$ & $t$ & $e(t)$ & $R^{2}$ \\
\hline Combined effect & 0 & $( \pm)$ & $8.10^{-}$ & $( \pm) 2.10^{-}$ & 281 & $( \pm) 7.10^{-}$ & 0.978 \\
& 0 & ${ }_{5}$ & & & & & \\
\hline
\end{tabular}

$y=y_{0}+A_{1} e^{\left(x / t_{1}\right)}$ resulting in $y=A e^{(x / t)}$ (with $e(i)$ the error on parameter $i$ )

\section{Acknowledgements}

The authors would like to thank VLIR-UOS (Flemish Interuniversity Council for University Development Cooperation) project between Belgium and Cuba for providing funding and granting the support of the current and future studies.

\section{Authors' contributions}

JPT and HCS conceived, designed and performed the experiments. JPT, HCS and $J Y$ analyzed the data. JNC advised the research as rum specialist. JPT, $H C S, J Y, A B S$ and RC wrote the paper. All authors read and approved the final manuscript.

\section{Ethics approval}

None.

\section{Competing interests}

The authors declare that they have no competing interests.

\section{Publisher's Note}

Springer Nature remains neutral with regard to jurisdictional claims in published maps and institutional affiliations.

\section{Author details}

${ }^{1}$ Faculty of Electrical Engineering, Universidad de Oriente, Santiago de Cuba, Cuba. ${ }^{2}$ Faculty of Chemical Engineering, Energetic Efficiency Center,

Universidad de Oriente, Santiago de Cuba, Cuba. ${ }^{3}$ Research group of Applied and Analytical Chemistry, Hasselt University, Agoralaan building D, 3590

Diepenbeek, Belgium. ${ }^{4}$ First Master of Cuban Rum, Santiago de Cuba 905000 , Cuba.

Received: 28 July 2017 Accepted: 18 December 2017

Published online: 05 January 2018

\section{References}

Artajona SJ. Characterisation of oak wood according to its origin and burning degree by GC and HPLC. Viticul Enol Professional. 1991;14:61-72.

ASTM. Standard test methods for moisture in activated carbon, D 2867-04. West Conshohocken: ASTM International; 2011.

Cherry RN Jr. lonizing radiations: American National Standards Institute (ANSI); 1993.

Crespo Sariol H, Mariño Peacok T, Yperman J, Sánchez Roca Á, Carvajal Fals H, Brito Sauvanell Á, Carleer R, Czech J, Leda Vargas JR, Navarro Campa J. Comparative study between acoustic emission analysis and immersion bubble-metric technique, TGA and TD-GC/MS in view of the characterization of granular activated carbons used in the rum production. Beverages. 2017b; $3: 12$.

Crespo Sariol H, Maggen J, Czech J, Reekmans G, Reggers G, Adriaensens P, Yperman J, Brito Sauvanell Á, Carleer R, Navarro Campa J. Characterization of the exhaustion profile of activated carbon in industrial rum "filters" based on TGA, TD-GC/MS, colorimetry and NMR relaxometry. Mat Today Comm. 2017a; 11:1-10.

Crespo Sariol H, Mariño Peacok T, Yperman J, Brito Sauvanell Á, Carleer R, Navarro Campa J. Characterization of granular activated carbons used in the rum production by immersion bubble-metric technique in a pure liquid. J Food Process Bev. 2016c;4:1-10.

Crespo Sariol H, Vanreppelen K, Yperman J, Brito Sauvanell Á, Carleer R, Navarro Campa J. A colorimetric method for the determination of the exhaustion level of granular activated carbons used in the rum production. Beverages. 2016a;2:24.

Crespo Sariol H, Yperman J, Brito Sauvanell Á, Carleer R, Navarro Campa J, Gryglewicz G. A novel acoustic approach for the characterization of granular activated carbons used in the rum production. Ultrasonics. 2016b;70:53-63.

Cunningham JR. The Physics of Radiology. Springfield, ISBN: 0-398-04669-7: Charles C Thomas Publisher; 1986. p. 81-21396.

De Souza M, Vázquez P, Del Mastro N, Acree T, Lavin J. Characterization of Cachaça and rum aroma. Journal of Agric Food Chem. 2006;54:485-8.

Ferhan C, Aktas O. Activated carbon for water and wastewater treatment Istambul: WILEY-VCH Verlag GmbH \& Co. K Ga A; 2011. p. 46-321.

Gonzales RC, Woods RE. Digital image processing. 2nd ed. Upper Saddle River: Prentice Hall; 2002. 
Gonzales RC, Woods RE, Eddins SL. Digital image processing using Matlab. Upper Saddle River: Prentice Hall; 2004

Jorge AP. Characterization of rum using solid-phase micro extraction with gas chromatography-mass spectrometry. Food Chem. 2007;104:421-8.

Jorge AP, Sebastian T, Recep G, Winterhalter P. Characterisation of odor-active compounds in aged rum. Food Chem. 2012;132:1436-41.

Juan M, Tascón D, Bottani EJ. Adsorption by carbons: Elsevier Ltd, ISBN: 978-0-08044464-2; 2008. p. 79-685.

Klobes $P$, Meyer K. Porosity and specific surface area measurements for solid materials. Washington, DC: NIST Spec. Publ. 960-17; 2006. p. 10-82.

Maga JA. The contribution of wood to the flavour of alcoholic beverages. Food Rev. 1989;5:39-99.

Marsh H, Rodriguez-Reynoso F. Activated carbon: Elsevier Science \& Technology Books, ISBN: 0080444636; 2006. p. 13-317.

Nabeta K, Onishi M, Masuda M, Koda M, Matsuyama R. In: Pigott JR, editor. Reaction of wood components during maturation in flavour of distilled beverages: origin and development. Chichester: Horwood; 1983. p. 241-55.

Nykanen L, Moring I. Aroma compounds dissolved from oak chips by alcohol. Dev Food Sci. 1984;10:339-46.

Nykanen L, Nykanen I. Flavour components in distilled beverages. Helsinki: Alko Ltd; 1991.

Otzuka K, Morinaga M. Study of the mechanism of ageing of distilled liquors part II. Distribution of phenolic compounds in aged distilled liquors. Agric Biol Chem Col. 1965;29(1):27-31.

Parfait A, Jouret C. Formation of higher alcohols in rum. Annales de Technologie Agricole. 1975:421-36.

Queris HO. Science and technologies of distillates beverages. Res Inst of Food Ind of Cuba. 2007;11:19.

Queris O, Sánchez M. Efecto del tostado de la viruta de roble sobre la composición de los extractos. La Habana: Food Res. Inst. of Cuba; 1998. (In Spanish)

Reazin G. Chemical mechanism of whisky maturation. Am J Enol Vitic. 1981;32: 283.

Rouquerol J, Rouquerol F, Sing KSW, Llewellyn P, Maurin G. Adsorption by powders and porous solids: principles, methodology and applications: Academic Press; 2014

Sarni F, Moutonet M, Puech JL, Rabier P. Effects of heat treatment of oak wood extractable compound. Holzforchung. 1990;44:461-6.

Schiith F, Kenneth S, Sing W, Weitkamp J. Handbook of porous solids. Weinheim, ISBN 3-527-3024-8: WILEY-VCH Verlag GmbH; 2002. p. 156-293.

Semmlow JL. Biosignal and biomedical image processing. Piscataway: Rutgers University; 2004. ISBN: 0-8247-4803-4

Sigmund G, Hüffer T, Hofmann T, Kah M. Biochar total surface area and total pore volume determined by $\mathrm{N} 2$ and $\mathrm{CO} 2$ physisorption are strongly influenced by degassing temperature. Sci Total Environ. 2016:1-6.

Sponholz K. Volatile fatty acids in Caribbean rums and rum blends. Deutsche Lebensmittel, Rundschau. 1990;86:80-1.

Suomalainenen M, Nykanen L. Investigation on the aroma of alcoholic beverages. Naeringsmiddelindustren. 1970;85:149-56.

Thomas WJ, Barry C. Adsorption technology and design: Elsevier Science \& Technology Books, ISBN: 0750619597; 1998. p. 28-212.

Worch E. Adsorption Technology in Water Treatment: Walter de Gruyter GmbH \& Co., ISBN 978-3-11-024022-1; 2012. p. 25-268.

\section{Submit your manuscript to a SpringerOpen ${ }^{\circ}$ journal and benefit from:}

- Convenient online submission

- Rigorous peer review

- Open access: articles freely available online

- High visibility within the field

- Retaining the copyright to your article 